\title{
Catalyzed Enantioselective Conjugate Addition Reactions of Strongly Coordinating Nucleophiles
}

\author{
Shuji Kanemasa \\ Institute for Materials Chemistry and Engineering, CREST of JST \\ (Japan Science and Technology), Kyushu University, \\ Received July 4, 2003

\begin{abstract}
This article describes a new synthetic methodology developed in our institute, which produces enantiomers in the reactions using strongly coordinating nucleophiles under the catalysis of torelant chiral Lewis acid. The nickel(II) aqua complexes derived from DBFOX chiral ligand can successfully catalyze the conjugate addition reactions of thiols. Even under double catalytic conditions using catalytic amounts of both amines and the DBFOX - nickel(II) complexes, Michael addition reactions of active methylene compounds such as malononitrile and nitromethane can be effectively activated.
\end{abstract}

\section{Introduction}

The trans-chelating tridentate chiral ligand, 4,6-dibenzofurandiyl-2,2'-bis(4-phenyloxazoline), designated as DBFOX/ $\mathrm{Ph} \mathbf{A}$, forms stable aqua complexes with a variety of transition metals having noncoordinating counter ions. These complexes act as excellent chiral Lewis acid catalysts in Diels-Alder reactions ${ }^{1}$ and nitrone dipolar cycloadditions. ${ }^{2}$ Noteworthy features of the nickel(II) aqua complex $\mathbf{B}$ of DBFOX/Ph ligand $\mathbf{A}$ are its high catalytic activity and tolerance to a variety of nucleophilic reagents. This catalyst $\mathbf{B}$ is isolable and can be stored for months in open air without loss of catalytic activity. It shows sufficient catalytic activity in the presence of coordinating additives such as ethers, water, alcohols, acids, and even amines. ${ }^{1}$ Therefore, we can expect that these catalysts can be successfully applied to the catalyzed asymmetric reactions using strongly coordinating or nucleophilic reagents.

In this article, the author describes enantioselective thiol conjugate additions ${ }^{3}$ and Michael additions under double catalytic conditions ${ }^{4}$ by use of the aqua DBFOX/Ph - nickel(II) complex catalyst B.

\section{Thiol Conjugate Additions}

Thiols have been studied as nucleophiles in the conjugate addition reactions to 3-(2-alkenoyl)-2-oxazolidinones. Stereoselective thiol conjugate additions catalyzed by a Lewis acid are interesting not only from the standpoint of biological and synthetic importance but also in view of the difficulty encountered in the catalyzed reactions using thiols in industry. ${ }^{5}$ Quite a number of asymmetric thiol conjugate addition reactions have been reported, ${ }^{6}$ but previous examples of enantioselective thiol conjugate additions have all been based on the activation of thiol nucleophiles by use of chiral base catalysts such as amino alcohols, ${ }^{7}$ the lithium thiolate complex of amino bisether, ${ }^{8}$ and a lantanoid tris(binaphthoxide). ${ }^{9}$ To the best of our knowledge, there are no examples reported for the enantioselective thiol conjugate additions through the activation of acceptors by the aid of chiral Lewis acid catalysts.

The aqua complex of $R, R-\mathrm{DBFOX} / \mathrm{Ph}$ - nickel(II) perchlorate $R, R-\mathbf{B}$ was prepared in situ by treatment of equimo- lar amounts (10 mol\%) of DBFOX/Ph ligand $\mathbf{A}$ with nickel(II) perchlorate hexahydrate in tetrahydrofuran (THF) by stirring at room temperature for $30 \mathrm{~min}$. Reaction of benzenethiol (1a, 1.1 equiv) with 3-crotonoyl-2-oxazolidinone (2a, 1 equiv) was so slow that it took about $24 \mathrm{~h}$ at room temperature until oxazolidinone $\mathbf{2 a}$ was all consumed (checked by tlc). After aqueous work-up, the mixture was purified through silica gel column chromatography to give the conjugate adduct 3a, whose enantiopurity was determined by chiral HPLC (Daicel Chiralcel OD-H with hexane 2-PrOH $(9: 1 \mathrm{v} / \mathrm{v}))$. The thiol adduct 3a was converted into the methyl ester without racemization by treatment with magnesium bromide methoxide in methanol at $0^{\circ} \mathrm{C}$. Optical rotation of the resulting methyl ester was compared with an authentic sample to determine the absolute configuration of 3a to be $3 S$. Thus, the thiol conjugate addition took place at the $\mathrm{Si}-$ face of the acceptor oxazolidinone $\mathbf{2 a}$.

Among a variety of DBFOX/Ph complexes examined as chiral catalysts, the nickel(II) aqua complex $\mathbf{B}$ was exceptionally effective. Although the magnesium and zinc complexes prepared from $\mathrm{DBFOX} / \mathrm{Ph}$ ligand $\mathbf{A}$ by treatment with $\mathrm{Mg}\left(\mathrm{ClO}_{4}\right)_{2}, \mathrm{Zn}\left(\mathrm{ClO}_{4}\right)_{2} \bullet 6 \mathrm{H}_{2} \mathrm{O}, \mathrm{Zn}(\mathrm{OTf})_{2}$, or $\mathrm{ZnI}_{2}$ showed satisfactory catalytic activity, the enantioselectivities observed in the catalyzed thiol conjugate additions were relatively poor. On the other hand, metal complexes prepared from the perchlorates of copper(II), iron(II), and manganese(II) ions showed only low catalytic activity. Reactions of a variety of thiols $\mathbf{1 b}-\mathbf{l}$ were catalyzed by the aqua nickel complex $\mathbf{B}$ to give the corresponding adducts $\mathbf{3 b} \mathbf{- 1}$ (Scheme 1). Satisfactorily high enantioselectivities as well as high chemical yields were observed with some exceptions when the reactions were performed in tetrahydrofuran (THF) at room temperature (under conditions A, see the table in Scheme 1).

Enantioselectivities were found to change sharply depending upon the reaction conditions including catalyst structure, reaction temperature, solvent, and additives. Some representative examples of such selectivity dependence are listed in Table 1 . The adduct 3a was formed with $79 \%$ ee ( $81 \%$ yield) when the reaction was catalyzed by the aqua nickel complex $\mathbf{B}$ at room temperature in dichloromethane. However, reactions either by use of the anhydrous complex $\mathbf{C}$, which was in situ prepared by consecutive treatment of $\mathrm{DBFOX} / \mathrm{Ph}, \mathrm{NiBr}_{2}$ 


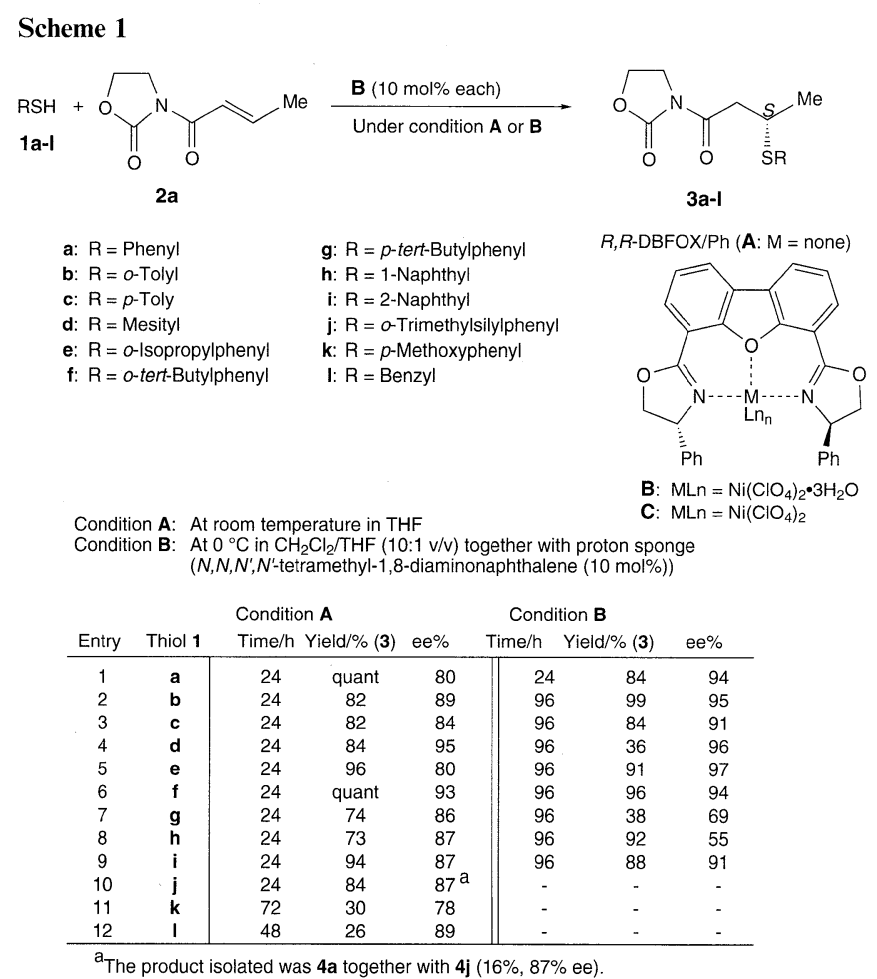

(10 mole $\%$ each), and $\mathrm{AgClO}_{4}(20 \mathrm{~mol} \%$ ), or the aqua complex $\mathbf{B}$ together with MS 4A gave racemic adduct $\mathrm{rac}^{-\mathbf{3 a}}$, indicating that the aqua complex should be more favored than the anhydrous complex in thiol conjugate additions (Scheme 1). Slow addition of thiol 1a to a dichloromethane solution of $\mathbf{2 a}$ was ineffective for enantioselectivity. Enantioselectivity was drastically lowered and reversed to $-17 \%$ ee in the reaction at $-78^{\circ} \mathrm{C}$. A similar tendency was observed in the reactions in diethyl ether and THF. For example, satisfactory enantioselectivity $(80 \%$ ee) was observed in the reaction in THF at room temperature, while the selectivity almost disappeared $(7 \%$ ee $)$ at $0^{\circ} \mathrm{C}$.

Table 1. Effect of reaction conditions in the reaction of thiophenol (1a) with 3-crotonoyl-2-oxazolidinone (2a) catalyzed by DBFOX/Ph complex $\mathbf{B}$ or $\mathbf{C}$

\begin{tabular}{|c|c|c|c|c|c|}
\hline Entry & Metal Salt ${ }^{a}$ & Solvent & $\mathrm{Temp} /{ }^{\circ} \mathrm{C}$ & Time/h & Yield $/ \%^{\mathrm{b}}$ \\
\hline $1^{d}$ & $\mathrm{Ni}\left(\mathrm{ClO}_{4}\right)_{2} \cdot 6 \mathrm{H}_{2} \mathrm{O}$ & $\mathrm{CH}_{2} \mathrm{Cl}_{2}$ & rt & 48 & 81 \\
\hline 2 & $\mathrm{NiBr}_{2}+2 \mathrm{AgClO}_{4}$ & $\mathrm{CH}_{2} \mathrm{Cl}_{2}^{2}$ & $\mathrm{rt}$ & 72 & 50 \\
\hline $3^{e}$ & $\mathrm{Ni}\left(\mathrm{ClO}_{4}\right)_{2} \cdot 6 \mathrm{H}_{2} \mathrm{O}$ & $\mathrm{CH}_{2} \mathrm{Cl}_{2}$ & $\mathrm{rt}$ & 24 & 91 \\
\hline $4^{d}$ & $\mathrm{Ni}\left(\mathrm{ClO}_{4}\right)_{2} \cdot 6 \mathrm{H}_{2} \mathrm{O}$ & $\mathrm{CH}_{2} \mathrm{Cl}_{2}$ & -78 & 48 & 33 \\
\hline 5 & $\mathrm{NiBr}_{2}+2 \mathrm{AgClO}_{4}$ & $\mathrm{Et}_{2} \mathrm{O}$ & it & 48 & 50 \\
\hline 6 & $\mathrm{Ni}\left(\mathrm{ClO}_{4}\right)_{2} \cdot 6 \mathrm{H}_{2} \mathrm{O}$ & $\mathrm{Et}_{2} \mathrm{O}$ & $\mathrm{rt}$ & 24 & 42 \\
\hline 7 & $\mathrm{Ni}\left(\mathrm{ClO}_{4}\right)_{2} \cdot 6 \mathrm{H}_{2} \mathrm{O}$ & THF & $\mathrm{rt}$ & 24 & quant \\
\hline 8 & $\mathrm{Ni}\left(\mathrm{ClO}_{4}\right)_{2} \cdot 6 \mathrm{H}_{2} \mathrm{O}$ & THF & 0 & 72 & 62 \\
\hline 9 & $\mathrm{Ni}\left(\mathrm{ClO}_{4}\right)_{2} \cdot 6 \mathrm{H}_{2} \mathrm{O}$ & $\mathrm{CH}_{2} \mathrm{Cl}_{2} / \mathrm{MeOH}(1 / 1)$ & $\mathrm{rt}$ & 24 & quant \\
\hline 10 & $\mathrm{Ni}\left(\mathrm{ClO}_{4}\right)_{2} \cdot 6 \mathrm{H}_{2} \mathrm{O}$ & $\mathrm{CH}_{2} \mathrm{Cl}_{2} / \mathrm{AcOH}(10 / 1)$ & $\mathrm{rt}$ & 48 & 99 \\
\hline 11 & $\mathrm{Ni}\left(\mathrm{ClO}_{3}\right) \cdot 6 \mathrm{H}_{2} \mathrm{O}$ & $\mathrm{CH}_{2} \mathrm{Cl} /$ sat. $\mathrm{NH}_{4} \mathrm{Cl}$ aq. $(10 / 1)$ & 1) $\mathrm{rt}$ & 48 & 99 \\
\hline
\end{tabular}

"Catalyst was prepared in situ from equimolar amounts of DBFOX/Ph and metal salt in $\mathrm{CH}_{2} \mathrm{Cl}_{2}$. ${ }^{\mathrm{b}}$ Isolated yield. 'Determined by chiral HPLC (Daicel Chiral Cel OD-H), ee $=\% \mathrm{~S}$ - \% R. ${ }^{2} \mathrm{DBFOX} / \mathrm{Ph}$ was added to a mixture of $\mathrm{Ni}\left(\mathrm{ClO}_{4}\right)_{2} \cdot 6 \mathrm{H}_{2} \mathrm{O}, \mathbf{1 a}$, and $2 \mathrm{a}$. ${ }^{\mathrm{e}}$ Thiophenol (1a) was added slowly to a mixture of DBFOX/Ph and $\mathbf{2}$ in a period of $3 \mathrm{~h}$.

To examine such high sensitivity of enantioselectivity to the reaction conditions, the reactions of benzenethiol (1a) with 3-crotonoyl-2-oxazolidinone (2a) were performed in dichloromethane at room temperature in the presence of a variety of additives. Although addition of methanol $\left(\mathrm{CH}_{2} \mathrm{Cl}_{2} / \mathrm{MeOH}=10: 1 \mathrm{v} / \mathrm{v}\right)$ did not affect either the chemi- cal yield or enantioselectivity of $\mathbf{3 a}$ (quant, $82 \%$ ee), addition of acetonitrile or $N, N$-dimethylformamide (both $1: 1 \mathrm{v} / \mathrm{v}$ ratios) slowed the reactions $(13,15 \%$ yields of $\mathbf{3 a})$ and provided products with lower enantioselectivities (19, 30\% ees). The presence of acetic acid, even in a small amount $\left(\mathrm{CH}_{2} \mathrm{Cl}_{2} / \mathrm{AcOH}=10: 1 \mathrm{v} / \mathrm{v}\right)$, gave the racemic product, while saturated aqueous ammonium chloride provided reversed enantioselectivity $\left(\mathrm{CH}_{2} \mathrm{Cl}_{2} / \mathrm{sat} . \mathrm{NH}_{4} \mathrm{Cl}\right.$ aq. $=10: 1 \mathrm{v} / \mathrm{v}, 99 \%$ yield, $-27 \%$ ee). However, to our delight, the reaction in a mixed solvent of $\mathrm{CH}_{2} \mathrm{Cl}_{2} / \mathrm{THF}=10: 1 \mathrm{v} / \mathrm{v}$ catalyzed by the aqua nickel complex $\mathbf{B}$ at $0^{\circ} \mathrm{C}$ in the presence of $N, N, N^{\prime}, N^{\prime}$-tetramethyl-1,8-diaminonaphthalene (proton sponge, $10 \mathrm{~mol} \%$ ) gave the best result (3a: $84 \%$ yield, 94\% ee). Some other thiols provided excellent enantioselectivities under similar reaction conditions with $97 \%$ ee for a bulky thiol such as $O$-isopropylbenzenethiol 1e (Scheme 1).

We suspected at the beginning of this work that thiol 1a would strongly coordinate to the Lewis acid catalyst $\mathbf{B}$ to poison its catalytic activity. We therefore examined the interaction between thiol 1a and the catalyst $\mathbf{B}$ to learn about the catalytic activity of the thiol-coordinating complex. When 1a was added to the solution of $\mathbf{B}$ in THF, the original pale blue color of the catalyst gradually turned to reddish-brown, and this color change was even rapid in dichloromethane. Treatment of 1a with $\mathbf{B}$ in dichloromethane or diethyl ether immediately precipitated a brown solid which was found to be an active catalyst. Because of less solubility of this thiol complex, the reaction in dichloromethane or diethyl ether is less effective leading to low yields and enantioselectivities.

A brown-colored solid was isolated as precipitate upon treatment of the THF solution between $\mathbf{1 a}$ and $\mathbf{B}$ with a mixture of isopropyl alcohol and hexane. Although the resulting solid was found to be rather unstable to liberate thiol slowly at room temperature, it showed sufficient catalytic activity in the reaction of $\mathbf{1 a}$ with $\mathbf{2 a}$ in THF leading to high enantioselectivity $(97 \%$ yield, $70 \%$ ee). Accordingly, it is apparent that the thiol certainly binds with the catalyst $\mathbf{B}$, but the binding is not so strong that the thiol ligand may be easily replaced with the acceptor molecule $2 \mathbf{a}$ in the reaction. This ligand exchange should be more favored in a coordinating media such as THF. However, at the same time, THF competes with the acceptor molecule in coordination to the catalyst to deactivate the reaction.

In the presence of an amine base such as pyridine or triethylamine, a totally inert reddish-brown complex immediately precipitated. This complex was negative and positive in the halogen and sulfur tests, respectively, and no liberation of thiol 1a was detected. Although this complex is soluble in acetone, THF, and dichloromethane, no catalytic activity was observed in the thiol conjugate addition. Since the resulting brown solid is free of perchlorate ions, we assume that the perchlorate counter ions have been replaced with the highly nucleophilic thiolate ions to lose catalytic activity.

The time dependence of enantioselectivity in the reaction between $\mathbf{1 a}$ and $\mathbf{2 a}$ catalyzed by $\mathbf{B}$ at room temperature in THF is shown in Table 2. After $3 \mathrm{~h}$, the yield of $\mathbf{3 a}$ is $70 \%$ with enantioselectivity of $91 \%$ ee, but the enantioselectivity was $80 \%$ ee at the completion of reaction after $24 \mathrm{~h}$ (yield of 3a: $100 \%$ ). Although the catalyst maintains high catalytic activity, and hence a satisfactory enantioselectivity, at the early stage of reaction, the deterioration of the catalyst can- 
Table 2. Time dependence of yield and enantioselectivity in the reaction of $\mathbf{1 a}$ with $\mathbf{2 a}$ catalyzed by $\mathbf{B}$ at room temperature in $\mathrm{THF}$

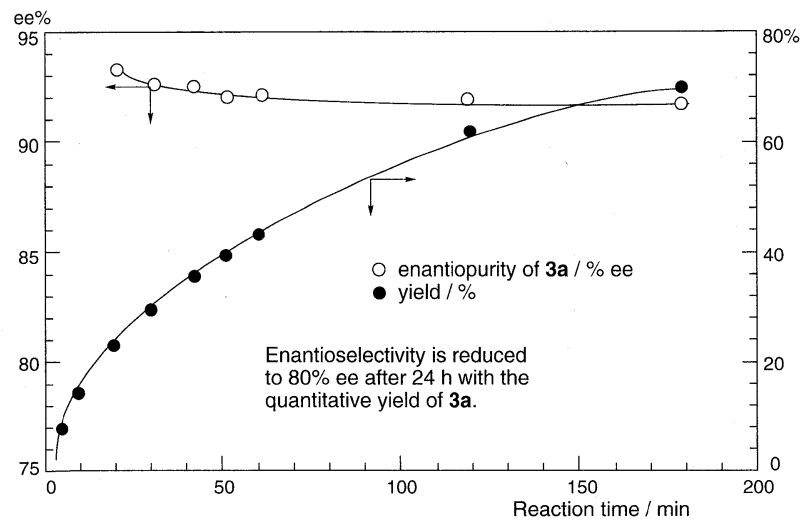

not be disregarded thereafter even under neutral conditions.

In conclusion, thiol conjugate addition reactions to 3-crotonoyl-2-oxazolidinone have been effectively catalyzed by the aqua nickel(II) complex of $\mathrm{DBFOX} / \mathrm{Ph}$ to produce conjugate adducts in high chemical yields and enantioselectivities. This provides the first example of enantioselective thiol conjugate additions catalyzed by a chiral Lewis acid catalyst. Irreversible coordination of thiols to the catalyst takes place slowly under neutral conditions, but the catalytic activity is maintained for several hours from the beginning of reaction. Under the optimized conditions (in dichloromethane THF $(10: 1 \mathrm{v} / \mathrm{v})$ at $-20^{\circ} \mathrm{C}$ in the presence of $N, N, N^{\prime}, N^{\prime}$-tetramethyl-1,8-diaminonaphthalene $(10 \mathrm{~mol} \%))$, enantioselectivity as high as $97 \%$ ee has been attained with the catalytic loading of $10 \mathrm{~mol} \%$ of DBFOX/Ph $\cdot \mathrm{Ni}\left(\mathrm{ClO}_{4}\right)_{2} \cdot 3 \mathrm{H}_{2} \mathrm{O}$ catalyst.

\section{Michael Additions of Malononitrile}

Michael addition reactions are one of the most important carbon - carbon bond forming reactions in modern synthetic organic chemistry. ${ }^{10}$ Although a number of catalyzed variants of enantioselective Michael additions are known, most are based on the activation of metalated donors modified by chiral ligands; ${ }^{11}$ the activation of acceptors by chiral Lewis acid catalysts is quite rare. ${ }^{12,13}$ Shibasaki's method using chiral heterobimetallic complexes is based on a different concept in which electrophiles and nucleophiles are both activated by a single catalyst. ${ }^{14}$ The author describes in this article a new synthetic methodology where donors and acceptors are both activated separately by catalytic amounts of Lewis base and Lewis acid catalysts. He would like to name this synthetic method using Lewis acid and amine catalysts "a double catalytic activation method". It is apparent that the correct choice of Lewis acid catalysts is essential for the success of double catalytic reactions. ${ }^{15}$

Malononitrile as donor and chelating acceptors such as 3-(2-alkenoyl)-2-oxazolidinones and 1-(2-alkenoyl)4-bromo-3,5-dimethylpyrazoles have been chosen. The reactions are activated by use of catalytic amounts (10 mol\% each) of both amines and the aqua complex $\mathbf{B}$ derived from DBFOX/Ph A and nickel(II) perchlorate hexahydrate in either dichloromethane or tetrahydrofuran at room temperature to give the corresponding Michael adducts. Important factors operating in the reactions under the double catalytic activation conditions, such as the proper choice of chiral
Lewis acid and amine catalysts, chelating auxiliaries, reaction solvents, and additives, have been discussed.

Scheme 2

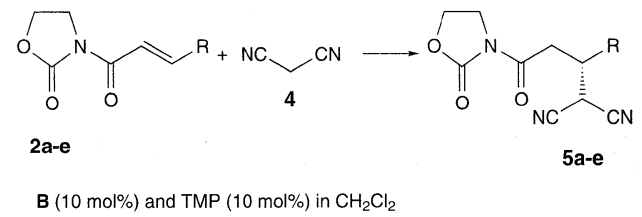

No reactions occur between 3-crotonoyl-2-oxazolidinone (2a) and malononitrile (4) without catalysts, and amines themselves do not work effectively. Achiral titanium catalysts such as $\mathrm{TiCl}_{2}\left(\mathrm{O}^{i} \mathrm{Pr}\right)_{2}$ also did not show any catalytic activity. However, a chiral Lewis acid DBFOX/Ph $\cdot \mathrm{Ni}\left(\mathrm{ClO}_{4}\right)_{2} \cdot 3 \mathrm{H}_{2} \mathrm{O}^{1 \mathrm{~b}}$ (B, $10 \mathrm{~mol} \%$ ) activated the same reaction giving the Michael adduct $5 \mathbf{a}$ without amines (rt, $72 \mathrm{~h}, 40 \%, 5 \%$ ee, Scheme 2), and $\mathrm{DBFOX} / \mathrm{Ph} \cdot \mathrm{Mg}\left(\mathrm{ClO}_{4}\right)_{2}$ showed even more effective activation ( $\mathrm{rt}, 48 \mathrm{~h}, 45 \%, 86 \%$ ee). Among the Lewis acid catalysts examined in the reactions under the double catalytic activation conditions, the DBFOX/Ph complex B derived from $\mathrm{Ni}\left(\mathrm{ClO}_{4}\right)_{2} \cdot 6 \mathrm{H}_{2} \mathrm{O}$ showed much higher catalytic activity and enantioselectivity than other $\mathrm{DBFOX} / \mathrm{Ph}$ complexes derived from other metal perchlorates such as $\mathrm{Zn}\left(\mathrm{ClO}_{4}\right)_{2} \bullet 6 \mathrm{H}_{2} \mathrm{O}, \mathrm{Cu}\left(\mathrm{ClO}_{4}\right)_{2} \bullet 6 \mathrm{H}_{2} \mathrm{O}$, and $\mathrm{Fe}\left(\mathrm{ClO}_{4}\right)_{3} \bullet \mathrm{nH}_{2} \mathrm{O}$. When a catalytic amount of 2,6-lutidine $(10 \mathrm{~mol} \%)$ was added to the reaction catalyzed by $\mathbf{B}$, adduct $\mathbf{5} \mathbf{a}$ was given in $90 \%$ yield ( $\mathrm{rt}, 4 \mathrm{~h}, 76 \%$ ee). Based on the rate enhancement and moderate enantioselectivity observed, the effective activation of acceptor $\mathbf{2 a}$ by coordination to the chiral Lewis acid catalyst $\mathbf{B}$ was achieved even in the presence of an amine catalyst. Thus, the suspected fatal deactivation of the Lewis acid catalyst by the strong binding of amine was a groundless anxiety in this case.

Table 3. Effect of amines in reaction of $\mathbf{2 a}$ to $\mathbf{4}$ catalyzed by $\mathbf{B}$ $(10 \mathrm{~mol} \%)$

\begin{tabular}{lcccr} 
Amine (10 mol\%) & Temp $/{ }^{\circ} \mathrm{C}$ & Time/h & Yield $/ \%$ & $\%$ ee \\
\hline none & $\mathrm{rt}$ & 72 & 40 & 5 \\
Proton sponge & -20 & 18 & 92 & 85 \\
$i$-Pr ${ }_{2}$ EtN & -20 & 24 & quant & 87 \\
DBU & -20 & 96 & 70 & 87 \\
$N, N$-Dibenzylamine & -20 & 32 & quant & 82 \\
$N, N$-Dicyclohexylamine & -20 & 8 & 85 & 82 \\
TMP & -20 & 6 & 90 & 85 \\
\hline
\end{tabular}

Therefore, a variety of amine catalysts $(10 \mathrm{~mol} \%)$ were examined in the reaction of $\mathbf{2 a}$ with $\mathbf{4}$ in the presence of Lewis acid catalyst $\mathbf{B}(10 \mathrm{~mol} \%)$. Some bulky amines were chosen with an expectation of minimized deactivation of the Lewis acid catalyst (Table 3). They include 1,8-bis(dimethylamino)naphthalene (proton sponge), ethyldiisopropylamine, 1,8-diazabicyclo[5.4.0]undec-7-ene (DBU), $N, N$-dibenzylamine, $N, N$-dicyclohexylamine, and 2,2,6,6-tetramethylpiperidine (TMP). These amines all worked well in the reactions performed at $-20^{\circ} \mathrm{C}$ to enhance the reaction rates resulting in the satisfactory improvement of yields and enantioselectivities for adduct 5a. Among these amines, TMP was selected in the enantioselective Michael additions of malononitrile (4) under the double catalytic activation conditions since this amine was best in terms of catalytic activity and enantioselectivity. Not only high basicity but also bulkiness of TMP provides such high synthetic advantage. Bulky 
amines like TMP should be less coordinating to the metallic center of complex $\mathbf{B}$ so that deactivation of the Lewis acid catalyst is relatively avoided.

Table 4. Reactions of $\mathbf{2 a - e}$ with 4 catalyzed by $\mathbf{B}$ and TMP (10 $\mathrm{mol} \%$ each) in dichloromethane

\begin{tabular}{lccrccc}
$\mathrm{R}$ & Alkene & Temp $^{\circ} \mathrm{C}$ & Time/h & Adduct & Yield $/ \%$ & $\%$ ee \\
\hline $\mathrm{Me}$ & $\mathbf{2 a}$ & -20 & 6 & $\mathbf{5 a}$ & 90 & 85 \\
$n-\mathrm{Pr}$ & $\mathbf{2 b}$ & -20 & 96 & $\mathbf{5 b}$ & quant & 90 \\
$i-\mathrm{Pr}$ & $\mathbf{2 C}$ & -20 & 48 & $\mathbf{5 c}$ & 90 & 87 \\
$t-\mathrm{Bu}$ & $\mathbf{2 d}$ & 0 & 168 & $\mathbf{5 d}$ & 58 & 90 \\
$t-\mathrm{Bu}$ & $\mathbf{2 d}$ & -20 & 168 & $\mathbf{5 d}$ & 38 & 94 \\
$\mathrm{Ph}$ & $\mathbf{2 e}$ & $\mathrm{rt}$ & 96 & $\mathbf{5 e}$ & 95 & 75 \\
\hline
\end{tabular}

In the reaction of $\mathbf{2 a}$ with $\mathbf{4}$ under the double catalytic activation conditions, the nickel(II) aqua complex $\mathbf{B}$ derived from DBFOX/Ph A and $\mathrm{Ni}\left(\mathrm{ClO}_{4}\right)_{2} \cdot 6 \mathrm{H}_{2} \mathrm{O}$ gave the highest catalytic activity for the formation of $\mathbf{5 a}$. Although the magnesium complex DBFOX/Ph $\bullet \mathrm{Mg}\left(\mathrm{ClO}_{4}\right)_{2}$ showed the highest catalytic activity in the reactions without an amine catalyst, it was seriously deactivated in the presence of triethylamine ( $\mathrm{rt}$, $96 \mathrm{~h}, 26 \%, 26 \%$ ee). Binding of amine to the magnesium ion is probably stronger than that to the hydrated nickel(II) ion. At the end, the reactions of a variety of 3-(2-alkenoyl)2-oxazolidinones $\mathbf{2 a - e}$ with $\mathbf{4}$ were performed under the optimized double catalytic activation conditions using Lewis acid B and TMP catalysts (10 mol\% each) in dichloromethane, mostly at $-20^{\circ} \mathrm{C}$ and in other cases at $0^{\circ} \mathrm{C}$ to $\mathrm{rt}$, to provide enantiomers of Michael adducts 5a-e (Table 4). When the catalytic amounts of amines were reduced, both catalytic activity and enantioselectivities were much decreased. Sometimes, when reactions are performed under a lower temperature such as -40 to $-78^{\circ} \mathrm{C}$, unexpectedly low enantioselectivities result. The reason has remained unsolved.

Chiral HPLC analysis was not effective to determine the enantioselectivities of adducts 5a-d. Therefore, they were transformed into the corresponding benzyl esters $\mathbf{6 a - d}$ in good yields by treatment with lithium benzyloxide (THF, $0^{\circ} \mathrm{C}, 5 \mathrm{~min}$, Scheme 3), and the enantioselectivities of Michael adducts $\mathbf{5 a}-\mathbf{d}$ were found to be satisfactory on the basis of the chiral HPLC analysis of 6a-d on Daicel Chiral Cell OD-H (85 to $90 \%$ ee, Table 4). Although the highest enantioselectivity of $94 \%$ ee was recorded when the $\beta$-substituent is bulky as $2 \mathbf{d}$, the reaction was very slow at $-20^{\circ} \mathrm{C}$, and therefore the reaction temperature was raised to $0^{\circ} \mathrm{C}$. The aryl-substituted substrate $2 \mathbf{e}$ is also less reactive, reaction at room temperature giving an enantioselectivity of $75 \%$ ee.

Scheme 3

$$
\begin{aligned}
& \text { 5a-e }+\underset{3 \text { equiv }}{\mathrm{PhCH}_{2} \mathrm{OH}} \frac{n \text {-BuLi (2.4 equiv) }}{\text { in } \mathrm{THF}, 0^{\circ} \mathrm{C}, 5 \mathrm{~min}} \\
& \text { 6a-d } \\
& \text { a: } R=M e(88 \%) \\
& \text { b: } \mathrm{R}=n-\operatorname{Pr}(88 \%) \\
& \text { c: } \mathrm{R}=i \operatorname{Pr}(88 \%) \\
& \text { d: } \mathrm{R}=t \text {-Bu (85\%) }
\end{aligned}
$$

Although dichloromethane was effectively used in the reaction of $\mathbf{2 a}$ with $\mathbf{4}$, some polar solvents could also be employed (Table 5). Thus, acetonitrile was a good solvent for the same reaction at room temperature, but the reaction rate became unexpectedly slow at $-20^{\circ} \mathrm{C}$. A $1: 1 \mathrm{v} / \mathrm{v}$ mixture of acetonitrile and THF was an even better solvent and enantioselectivity of $75 \%$ ee was observed for $\mathbf{5 a}$. When dichloromethane was diluted with a small amount of THF $(10: 1 \mathrm{v} / \mathrm{v})$ or methanol $(10: 3 \mathrm{v} / \mathrm{v})$, the reaction rates remained fast to give quantitative yields of $\mathbf{5 a}$ with satisfactory enantioselectivities even at lower reaction temperatures.

Table 5. Solvent effects in the reactions of $\mathbf{2 a}$ to $\mathbf{4}$ catalyzed by $\mathbf{B}$ and TMP (10 mol\% each)

\begin{tabular}{lcccc} 
Solvent & Temp/ $/{ }^{\circ} \mathrm{C}$ & Time/h & Yield $/ \%$ & $\%$ ee \\
\hline $\mathrm{MeCN}$ & $\mathrm{rt}$ & 1.5 & 89 & 69 \\
$\mathrm{MeCN}$ & -20 & 120 & 23 & 74 \\
$\mathrm{MeCN}: \mathrm{THF}=1: 1 \mathrm{v} / \mathrm{v}$ & $\mathrm{rt}$ & 1.5 & 92 & 75 \\
$\mathrm{CH}_{2} \mathrm{Cl}_{2}: \mathrm{THF}=10: 1 \mathrm{v} / \mathrm{v}$ & 0 & 4 & 98 & 81 \\
$\mathrm{CH}_{2} \mathrm{Cl}_{2}: \mathrm{MeOH}=10: 3 \mathrm{v} / \mathrm{v}$ & -20 & 24 & quant & 84 \\
\hline
\end{tabular}

Polar solvents should prevent the coordination of acceptor $\mathbf{2}$ to the chiral catalyst $\mathbf{B}$ resulting in deceleration of reaction, but at the same time such solvents should work to suppress the undesired coordination of amine to the catalyst $\mathbf{B}$. These two counterbalancing interactions always compensate each other. This is a pattern usually observed in enantioselective reactions under the double catalytic activation conditions. Good balance of the activating and deactivating factors is important.

We next utilized 1-crotonoyl-3,5-dimethylpyrazole (7a) as Michael acceptor in the reaction of malononitrile (4) as shown in Scheme 4. Again, no reactions took place between 4 and 7a without catalysts, and only a slow reaction proceeded in the presence of an amine catalyst (TMP, $10 \mathrm{~mol} \%$, rt, $96 \mathrm{~h}, 17 \%$ of 9). Although the complex $\mathbf{B}$ worked as an active catalyst to enhance the reaction between $\mathbf{4}$ and $7 \mathbf{a}$, catalytic activity as well as enantioselectivity was not sufficient both in dichloromethane ( $\mathrm{rt}, 24 \mathrm{~h}, 57 \%, 51 \%$ ee) and in THF ( $\mathrm{rt}, 96 \mathrm{~h}, 67 \%, 75 \%$ ee). However, the use of TMP as the amine catalyst together with $\mathbf{B}(10 \mathrm{~mol} \%$ each $)$ was again effective.

\section{Scheme 4}

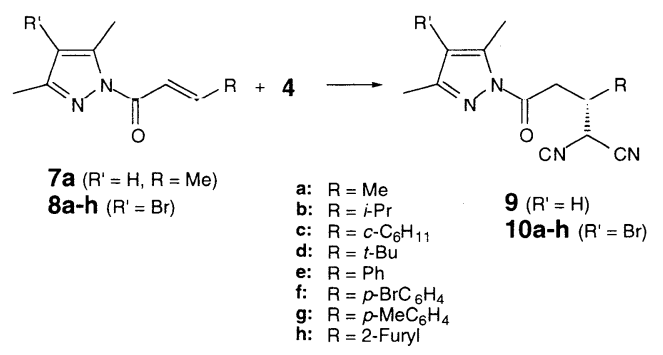

Table 6. Role of acetic anhydride in the reactions of $\mathbf{4}$ to $7 \mathbf{a}$ catalyzed by $\mathbf{B}$ and TMP (10 mol\% each)

\begin{tabular}{ccccc}
$\mathrm{Ac}_{2} \mathrm{O}$ (equiv) & $\mathrm{Temp}^{\circ} \mathrm{C}$ & $\mathrm{Time} / \mathrm{h}$ & Yield $/ \%$ & $\%$ ee \\
\hline none & $\mathrm{rt}$ & 5 & 86 & 23 \\
1 & $\mathrm{tt}$ & 6 & 89 & 81 \\
0.1 & $\mathrm{rt}$ & 6 & 82 & 81 \\
\hline
\end{tabular}

In the reaction of $\mathbf{4}$ to pyrazole substrate $7 \mathbf{a}$ under double catalytic activation conditions, the presence of a catalytic amount of acetic anhydride $(10 \mathrm{~mol} \%)$ worked to improve the chemical yields and enantioselectivities of 9 where THF was a good solvent (Table 6). The acceptors $\mathbf{8 a}-\mathbf{h}$ derived from 4-bromo-3,5-dimethylpyrazole were found to be more reactive than 7a and higher enantioselectivities were given for $\mathbf{1 0 a}-\mathbf{h}$. Thus, the Michael addition reactions of $\mathbf{4}$ to bromopyrazole substrates $\mathbf{8} \mathbf{a}-\mathbf{h}$ were performed in THF at room 
Table 7. Reactions of $\mathbf{7}$ or $\mathbf{8}$ with $\mathbf{4}$ catalyzed by $\mathbf{B}$ and TMP $(10 \mathrm{~mol} \% \text { each })^{\mathrm{a}}$

\begin{tabular}{|c|c|c|c|c|c|}
\hline$R$ & Alkene & Time/h & Adduct & Yield/\% & $\%$ ee \\
\hline $\mathrm{Me}$ & 7 & 5 & 9 & 94 & 81 \\
\hline $\mathrm{Me}$ & $8 a$ & 6 & $10 a$ & 92 & 88 \\
\hline$M e^{b}$ & $8 a$ & 5 & $10 a$ & 89 & 86 \\
\hline$i-\operatorname{Pr}$ & $8 b$ & 7 & $10 b$ & 94 & 93 \\
\hline$c-\mathrm{C}_{6} \mathrm{H}_{11}$ & $8 c$ & 24 & $10 c$ & 88 & 90 \\
\hline$t$-Bu & 8d & 120 & $10 d$ & 82 & 91 \\
\hline $\mathrm{Ph}$ & $8 \mathrm{e}$ & 12 & $10 e$ & 87 & 88 \\
\hline$p-\mathrm{BrC}_{6} \mathrm{H}_{4}$ & $8 f$ & 12 & $10 f$ & 94 & 85 \\
\hline$p-\mathrm{MeC}_{6} \mathrm{H}_{4}$ & $8 \mathrm{~g}$ & 24 & $10 \mathrm{~g}$ & 91 & 78 \\
\hline 2-Furyl & $8 h$ & 48 & $10 \mathrm{~h}$ & 78 & 55 \\
\hline
\end{tabular}

temperature in the presence of acetic anhydride (10 $\mathrm{mol} \%)$ under double catalytic activation conditions using chiral Lewis acid $\mathbf{B}$ and TMP (10 mol\% each). Not only acceptors with $\beta$-alkyl substituents $\mathbf{8 a}-\mathbf{d}$ but also those with $\beta$-aryl substituents 8e,f showed satisfactory enantioselectivities for the reactions performed at room temperature to give Michael adducts 10a-f (Table 7). Poor reactivity and lower enantioselectivities were observed for the acceptors $\mathbf{8 g}, \mathbf{h}$ with electron-rich aryl and furyl substituents.

The absolute configuration of Michael adduct 10d, produced in the reaction catalyzed by $R, R-\mathbf{B}$, was determined to be the $S$-enantiomer on the basis of the X-ray crystallography as shown in Figure 1, indicating that the Re-face of 10d was involved in the attack of malononitrile (4). Other adducts $\mathbf{1 0 a}-\mathbf{h}$, as well as $\mathbf{5 a}-\mathbf{e}$, were similarly assigned on the basis of the assumed reaction mechanism.

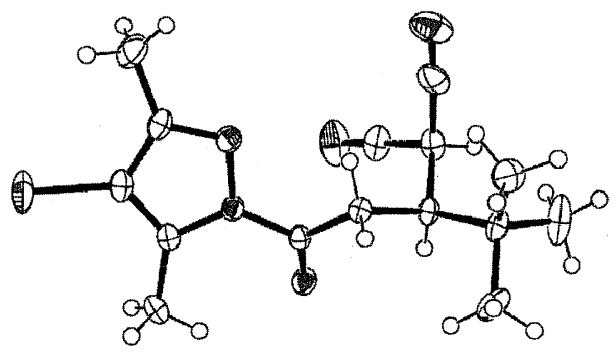

Figure 1. X-Ray determined structure of 10d.

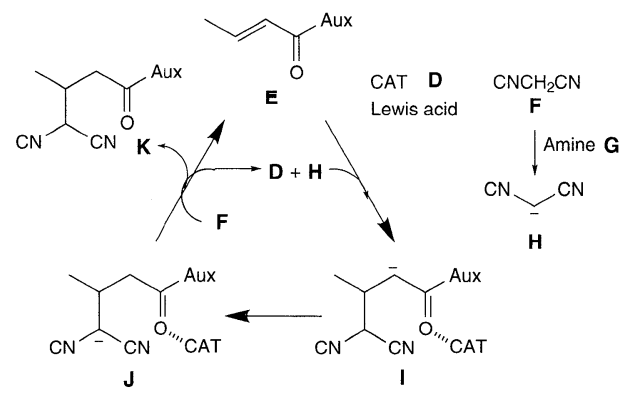

Figure 2. Michael additions under CDAM conditions.

The enantioselective Michael additions of malononitrile under the double catalytic activation conditions are most likely to proceed through the catalytic cycle shown in Figure 2. Amine catalyst $\mathbf{G}$ induces deprotonation of malononitrile $\mathbf{F}$ to generate malononitrile anion $\mathbf{H}$ which then undergoes enantioselective Michael addition to the reactive complex between electron-deficient alkene $\mathbf{E}$ and chiral catalyst $\mathbf{D}$ to give the enantiomer of adduct anion $\mathbf{I}$. The resulting metal-bound enolate I should be a stronger base than the dicyano-stabilized carbanion $\mathbf{J}$ so that intramolecular protonation of $\mathbf{I}$ takes place easily leading to anion $\mathbf{J}$. Probably, intermolecular anion exchange between $\mathbf{J}$ and malononitrile $\mathbf{F}$ occurs to produce the Michael adducts $\mathbf{K}$ with the concurrent liberation of chiral Lewis acid catalyst $\mathbf{D}$ and malononitrile anion $\mathbf{H}$, which are then involved in the next catalytic cycle shown in Figure 2. ${ }^{16}$ When the stabilized anion $\mathbf{J}$ is trapped with another molecule of acceptor $\mathbf{E}$, the 2:1 adduct is formed. This is a possible side reaction. Actually, the formation of the 2:1 adduct has happened albeit in a poor yield. Especially, when the $\beta$-position of acceptors is unsubstituted, the 2:1 adduct formation becomes a major reaction path.

In conclusion, the catalytic double catalytic activation method has worked successfully in the enantioselective Michael additions of malononitrile either to 3-(2-alkenoyl)2-oxazolidinones or 1-(2-alkenoyl)-4-bromo-3,5-dimethylpyrazoles in the presence of catalytic amounts $(10 \mathrm{~mol} \%$ each) of DBFOX/Ph $\bullet \mathrm{Ni}\left(\mathrm{ClO}_{4}\right)_{2} \bullet 3 \mathrm{H}_{2} \mathrm{O}$ as chiral Lewis acid and TMP as amine catalyst. The corresponding Michael adducts have been produced in high chemical yields with satisfactory enantioselectivities.

\section{Michael Additions of Nitromethane}

Chiral Lewis acid-catalyzed enantioselective reactions provide one of the most powerful and economical synthetic approaches leading to a variety of enantiomers. Electrophiles are activated by coordination to a chiral Lewis acid catalyst and nucleophiles react preferentially with the resulting enantiopure electrophile / catalyst complexes to give enantiomerically enriched products. When the reactivity of nucleophiles is not sufficiently high enough to react smoothly with the electrophiles activated by coordination to the catalyst, effective enantiomer formation becomes difficult. Although additional activation of the nucleophiles by use of a base catalyst would be a possible solution, such combined use of two catalysts should cause a serious problem in which the acid and base catalysts strongly bind each other resulting in the disappearance of catalytic capability. Success would be realized only when both catalysts show separate catalytic activities when they are used together in one flask. ${ }^{7,15,17}$

We have found that the aqua DBFOX/Ph complex B derived from nickel(II) perchlorate hexahydrate shows high tolerance toward strongly nucleophilic substrates. Although highly coordinating nucleophiles do bind with the metallic center of the catalyst, the binding should be relatively weak to undergo rapid ligand exchange between such strong nucleophiles and electrophilic substrates. ${ }^{2,18}$ Thus, the transition metal aqua complexes of DBFOX/Ph show highly effective chirality control in cyclopentadiene Diels-Alder reactions even in the presence of a variety of amine additives. ${ }^{1 b, c}$ Accordingly, the DBFOX/Ph aqua complexes would be the chiral Lewis acid catalysts of our choice for the double activation method by use of both Lewis acid and base catalysts. ${ }^{3}$

In this section, we report a new synthetic methodology for the catalytic enantioselective Michael addition reactions of nitromethane. ${ }^{19}$ Therein, both $\alpha, \beta$-unsaturated carbonyl acceptors as electrophiles and nitromethane as nucleophile can be activated by catalytic amounts of chiral Lewis acid and amine catalysts, respectively. We propose this new catalytic method leading to enantiomers of products to be 
named "double catalytic activation method (DCAM)".,15

Scheme 5

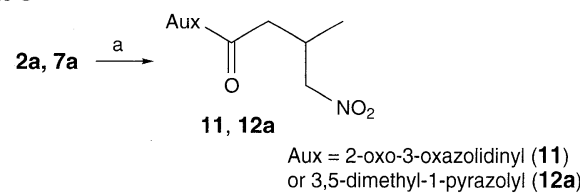

\begin{tabular}{llrrcc}
$\mathbf{2 , 7}$ & Conditions & Product & Time/h & Yield/\% & ee/\% \\
\hline 2a & $\mathrm{MeNO}_{2}$ as solvent & $\mathbf{1 1}$ & 144 & 30 & 39 \\
7a & $\mathrm{MeNO}_{2}$ (1 equiv) in THF & $\mathbf{1 2 a}$ & 168 & trace & - \\
& $\mathrm{MeNO}_{2}$ as solvent & $\mathbf{1 2 a}$ & 5 & 95 & 77 \\
& $\mathrm{MeNO}_{2}$ in THF $(1: 1 \mathrm{v} / \mathrm{v})$ & $\mathbf{1 2 a}$ & 5 & 97 & 84 \\
& $\mathrm{MeNO}_{2}$ in THF $(1: 1 \mathrm{v} / \mathrm{v}) / \mathrm{MS}$ & $\mathbf{1 2 a}$ & 5 & 84 & 67 \\
& & & & \\
\hline
\end{tabular}

a: In the presence of $\mathbf{B}$ and TMP (10 $\mathrm{mol} \%$ each), rt.

The reaction between nitromethane and 1-crotonoyl3,5-dimethylpyrazole (7a) was successfully induced in the presence of DBFOX/Ph $\cdot \mathrm{Ni}\left(\mathrm{ClO}_{4}\right)_{2} \bullet 3 \mathrm{H}_{2} \mathrm{O}($ B) and 2,2,6,6tetramethylpiperidine (TMP), both in catalytic amounts (10 $\mathrm{mol} \%$ ), in nitromethane to give 3-methyl-4-nitrobutanoyl-3,5-dimethylpyrazole (12a) as Michael adduct in 95\% yield $(77 \%$ ee) after $5 \mathrm{~h}$ at room temperature (Scheme 5). Although TMP as amine catalyst catalyzes the above reaction by itself $(10 \mathrm{~mol} \%, \mathrm{rt}, 72 \mathrm{~h}, 89 \%),{ }^{20} \mathbf{B}$ as Lewis acid shows no catalytic activity. An even more obvious example for the high activation of the nitromethane conjugate addition under DCAM conditions is the reaction with $\beta$-phenyl-substituted pyrazole $7 \mathbf{i}$ as acceptor: The adduct $\mathbf{1 2} \mathbf{i}$ was obtained in only $5 \%$ yield after $168 \mathrm{~h}$ at $\mathrm{rt}$ when the reaction was catalyzed by TMP alone $(10 \mathrm{~mol} \%)$, while the same reaction under DCAM conditions, even at $-20^{\circ} \mathrm{C}$, gave adduct $12 \mathbf{i}$ in $90 \%$ yield $(93 \%$ ee). Thus, the combined use of Lewis acid and amine catalysts works in a highly effective manner to accelerate Michael addition reactions with nitromethane.

Under the optimized conditions called standard conditions, the reaction of nitromethane with $7 \mathbf{a}$ was performed in a 1:1 vol/vol mixture of nitromethane and THF at room temperature $(5 \mathrm{~h})$ in the presence of $10 \mathrm{~mol} \%$ each of $\mathbf{B}$ and TMP Io give 12a in 97\% yield with enantioselectivity of $84 \%$ ee (Scheme 5). One advantage in the use of THF as cosolvent is that the preparation of catalyst $\mathbf{A}$ from the ligand $\mathbf{A}$ and $\mathrm{Ni}\left(\mathrm{ClO}_{4}\right)_{2} \cdot 6 \mathrm{H}_{2} \mathrm{O}$ can be completed in a few minutes at rt. As the Lewis acids, the DBFOX/Ph complex derived from $\mathrm{Ni}\left(\mathrm{ClO}_{4}\right)_{2} \bullet 6 \mathrm{H}_{2} \mathrm{O}$ was the most efective catalyst, and the aqua complex $\mathbf{B}$ showed both much higher reactivity and greater selectivity than the anhydrous complex catalyst DBFOX/ $\mathrm{Ph} \cdot \mathrm{Ni}\left(\mathrm{ClO}_{4}\right)_{2}(\mathrm{rt}, 48 \mathrm{~h}, \mathbf{1 2 a}: 19 \%, 31 \%$ ee). The same reaction catalyzed by the aqua complex $\mathbf{B}$ in the presence of MS 4A gave 12a in $84 \%$ yield with lower enantioselectivity of $67 \%$ ee. The DBFOX/Ph complex derived from $\mathrm{Co}\left(\mathrm{ClO}_{4}\right)_{2} \cdot 6 \mathrm{H}_{2} \mathrm{O}$ showed a little higher selectivity, but lower activity ( $\mathrm{rt}, 144 \mathrm{~h}$, 2a: $36 \%, 86 \%$ ee); however, other $\mathrm{DBFOX} / \mathrm{Ph}$ complexes derived from the following salts did not show any catalytic activity: $\mathrm{Zn}\left(\mathrm{ClO}_{4}\right)_{2} \bullet 6 \mathrm{H}_{2} \mathrm{O}, \mathrm{Cu}\left(\mathrm{ClO}_{4}\right)_{2} \bullet 6 \mathrm{H}_{2} \mathrm{O}, \mathrm{Mg}\left(\mathrm{ClO}_{4}\right)_{2} \bullet 6 \mathrm{H}_{2} \mathrm{O}$, $\mathrm{Zn}(\mathrm{OTf})_{2}, \mathrm{Cu}(\mathrm{OTf})_{2}$, and $\mathrm{Mg}(\mathrm{OTf})_{2}$.

Although a variety of amine catalysts could be utilized effectively, 2,2,6,6-tetramethylpiperidine (TMP) as a bulky amine gave the best balance of the catalytic activity and enantioselectivity. The reaction using 3-crotonoyl-2-oxazolidinone (2a) was much less reactive than the pyrazole substrate $\mathbf{7 a}$, indicating that the pyrazole acceptors 7 derived from 3,5-dimethylpyrazole were needed (Scheme 5).

Scheme 6
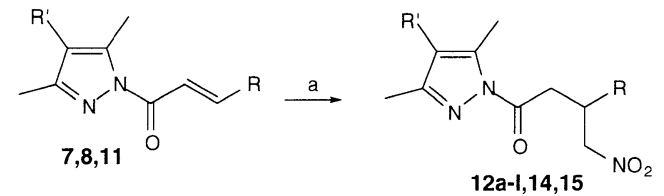

\begin{tabular}{|c|c|c|c|c|c|c|c|}
\hline $7,8,11$ & $\mathrm{R}$ & $\mathrm{R}^{\prime}$ & Temp $/{ }^{\circ} \mathrm{C}$ & Time/h & Product & Yield $/ \%$ & ee $/ \%$ \\
\hline \multirow[t]{3}{*}{$7 a$} & $\mathrm{Me}$ & $\mathrm{H}$ & $\mathrm{rt}$ & 5 & $12 a$ & 97 & 84 \\
\hline & & $\mathrm{H}$ & 0 & 48 & & 91 & 90 \\
\hline & & $\mathrm{H}$ & -20 & 96 & & 85 & 94 \\
\hline $8 \mathbf{a}$ & $\mathrm{Me}$ & $\mathrm{Br}$ & -20 & 96 & 14 & 97 & 95 \\
\hline 13 & $\mathrm{Me}$ & 1 & -20 & 96 & 15 & 62 & 96 \\
\hline $7 b$ & $\mathrm{Et}$ & $\mathrm{H}$ & 0 & 24 & $12 b$ & 93 & 94 \\
\hline $7 c$ & $n-\operatorname{Pr}$ & $\mathrm{H}$ & -20 & 96 & $12 c$ & 96 & 91 \\
\hline $7 d$ & $i-\operatorname{Pr}$ & $\mathrm{H}$ & -20 & 168 & $12 d$ & 74 & 97 \\
\hline $7 e$ & $c$-Hex & $\mathrm{H}$ & -20 & 168 & $12 e$ & 90 & 91 \\
\hline $7 f$ & $t-\mathrm{Bu}$ & $\mathrm{H}$ & 0 & 168 & $12 f$ & 39 & 95 \\
\hline $7 \mathrm{~g}$ & (E) $-\mathrm{MeCH}=\mathrm{CH}-$ & $\mathrm{H}$ & -20 & 96 & $12 \mathrm{~g}$ & 49 & 77 \\
\hline $7 \mathrm{~h}$ & $\mathrm{MeOOC}$ & $\mathrm{H}$ & it & 3 & $12 \mathrm{~h}$ & 91 & 83 \\
\hline $7 \mathbf{i}$ & $\mathrm{Ph}$ & $\mathrm{H}$ & -20 & 168 & $12 i$ & 90 & 93 \\
\hline $7 \mathbf{j}$ & $3,4-\left(\mathrm{OCH}_{2} \mathrm{O}\right) \mathrm{C}_{6} \mathrm{H}_{3}$ & $\mathrm{H}$ & -20 & 168 & $12 j$ & 77 & 98 \\
\hline $7 \hat{k}$ & 2-Furyl & $\mathrm{H}$ & -20 & 96 & $12 k$ & 75 & 97 \\
\hline 71 & 2-Thienyl & $\mathrm{H}$ & -20 & 168 & 121 & 83 & 97 \\
\hline
\end{tabular}

Finally, Michael additions of nitromethane with 1-(2-alkenoyl)-3,5-dimethylpyrazoles (7a-l) having a variety of $\beta$-substituents were found to take place smoothly under the standard conditions at $-20^{\circ} \mathrm{C}$ to produce the Michael adducts 12a-l (Scheme 6). Enantioselectivities up to $98 \%$ ee were observed. Acceptor substrates $\mathbf{7 a - f}$ with methyl and primary to tertiary alkyl substituents could be applied successfully, although acceptor 7f with a bulky $t$-butyl substituent is much less reactive. Other $\beta$-substituents such as 1 -alkenyl, ester, aryl, heteroaryl moieties work effectively.

Scheme 7

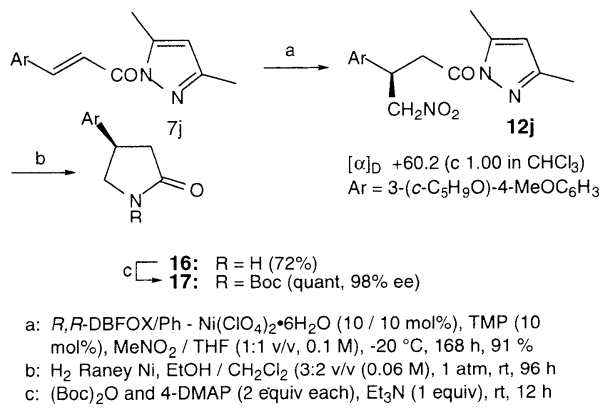

The synthetic potential of this new methodology of nitromethane conjugate additions under DCAM conditions could be demonstrated successfully in the effective and short-step synthesis of $(R)-(-)$-Rolipram $(16)^{21}$ known as an antidepressant and phosphodiesterase inhibitor (Scheme 7). The desired starting substrate $\mathbf{7} \mathbf{j}$ was synthesized by Wittig-Horner olefination of the substituted benzaldehyde, followed by transformation to the pyrazole amide in two steps. The optical yield of the Michael adduct $\mathbf{1 2} \mathbf{j}$ was determined to be $98 \%$ ee after its reductive conversion to $(R)$-Rolipram 16 followed by acylation to the $N$-Boc pyrrolidinone derivative 17. The absolute configuration of $\mathbf{1 6}$ was determined on the basis of the reported optical rotation, ${ }^{22}$ indicating that the $R e$-face of $7 \mathbf{j}$ was involved in the carbon-carbon bond formation step in the reaction catalyzed with the $R, R-\mathbf{B}$ catalyst.

In conclusion, we have presented a new synthetic method- 
ology for the enantioselective Michael addition reaction of nitromethane under double catalytic activation (DCAM), in which both $\alpha, \beta$-unsaturated carbonyl acceptors and nitromethane can be effectively activated by catalytic amounts of chiral Lewis acids and amine catalysts. For this purpose, the high tolerance of the DBFOX/Ph aqua complex catalyst $\mathbf{B}$ derived from nickel(II) perchlorate hexahydrate toward amine bases as well as an effective chirality induction was essential.

\section{Summary}

As mentioned above, the DBFOX/Ph aqua complex $\mathbf{B}$ derived from the chiral ligand $\mathbf{A}$ and nickel(II) perchlorate hexahydrate can be effectively employed in the enantioselective conjugate addition reactions using strongly coordinating nucleophiles. High tolerance based on the nickel(II) aqua complex catalyst $\mathbf{B}$ is apparently responsible for the great success achieved. The coordinating water ligands should make the metallic center of catalyst $\mathbf{B}$ more polar so that the polar local reaction fields are constructed. As a result, the rate of ligand exchange around the aqua nickel(II) metal becomes quite rapid, and consequently, high tolerance toward strongly coordinating nucleophiles results. So far, this aqua complex catalyst $\mathbf{B}$ can be effectively applied in the presence of amine catalysts to enable the double catalytic activation reaction. However, we have so far no answer why nickel(II) ions are especially superior.

\section{References}

1) (a) Kanemasa, S.; Oderaotoshi, Y.; Yamamoto, H.; Tanaka, J.; Wada, E.; Curran, D. P. J. Org. Chem. 1997, 62, 6454-6455. (b) Kanemasa, S.; Oderaotoshi, Sakaguchi, S.; Y.; Yamamoto, H.; Tanaka, J.; Wada, E.; Curran, D. P. J. Am. Chem. Soc. 1998, 120, 3074-3088. (c) Kanemasa, S.; Oderaotoshi, Y. J. Syn. Org. Chem. Jpn. 1998, 56, 368-376. (d) Kanemasa, S.; Oderaotoshi, Y.; Tanaka, J.; Wada, E. Tetrahedron Lett. 1998, 39, 7521-7524.

2) Kanemasa, S.; Oderaotoshi, Y.; Tanaka, J.; Wada, E. J. Am. Chem. Soc. 1998, 120, 12355-12356.

3) Kanemasa, S.; Oderaotoshi, Y.; Wada, E. J. Am. Chem. Soc., 1999, 121, 8675-8676.

4) (a) Itoh, K.; Kanemasa, S. J. Am. Chem. Soc. 2002, 124, 1339413395. (b) Ito, K.; Oderaotoshi, Y.; Kanemasa, S. Tetrahedron Asymm., 2003, 14, 635-639.

5) (a) "The Chemistry of the Thiol Group", ed. by Patai, S., Wiley, New York, 1974. (b) Ohno, A.; Oae, S. in "Organic Chemistry of Sulfur", ed. by Oae, S., Plenum, New York, 1976. (c) "Comprehensive Organic Chemistry, The Synthesis and Reactions of Organic Compounds", Sir Barton, D.; Ollis, W. D., "Sulphur, Selenium, Silicon, Boron, Organometallic Compounds" as Volume 3, ed. by Jones, D. N. pp. 3-20, Pergamon Press, Oxford, 1979.

6) Asymmetric thiol conjugate additions: (a) Koot, W.J.; Hiemstra, H.; Speckamp, W.N. Tetrahedron Asymm. 1993, 4, 19411948. (b) Wu, M.-J.; Wu, C.-C.; Tseng, T.-C. J. Org. Chem. 1994, 59, 7188-7189. (c) Tseng, T.-C.; Wu, M.-J. Tetrahedron Asymm. 1995, 6, 1633-1640. (d) Tomioka, K.; Muraoka, A.; Kanai, M. J. Org. Chem. 1995, 60, 6188-6190. (e) Schuurman, R. J. W.; Grimbergen, R. F. P.; Scheeren, H. W.; Nolte, R. J. M. Recl. Trav. Chim. Pays-Bas 1996, 115, 357-362. (f) Miyata, O.; Shinada, T.; Ninomiya, I.; Naito, T. Tetrahedron 1997, 53, 24212438.

7) (a) Hiemstra, H.; Wynberg, H. J. Am. Chem. Soc., 1981, 103, 417-430. (b) Suzuki, K.; Ikegawa, A.; Mukaiyama, T. Bull. Chem. Soc. Jpn. 1982, 55, 3277-3282. (c) Yamashita, H.; Mukaiyama, T. Chem. Lett. 1985, 363-366.

8) Nishimura, K.; Ono, M.; Nagaoka, Y.; Tomioka, K. J. Am. Chem. Soc. 1997, 119, 12974-12975.

9) Emori, E.; Arai, T.; Sasai, H.; Shibasaki, M. J. Am. Chem. Soc. 1998, 120, 4043-4044.
10) (a) Oare, D. A.; Heathcock, C. H. Top. Stereochem. 1991, 20, 87-170. (b) Trost, B. M.; Fleming, I. Comprehensive Organic Synthesis; Pergamon Press: Oxford, U. K., 1991; Vol. 4, pp 1-236. (c) Perlmutter, P. Conjugate Addition Reactions in Organic Synthesis; Pergamon Press: Oxford, U.K., 1992. (d) Perlmutter, P. In Advances in Asymmetric Synthesis; Stephenson, G. R., Ed.; Chapman \& Hall: London, U. K., 1996; pp 222-230. (e) Krause, N.; Hoffmann-Roder, A. Synthesis 2001, 171-196.

11) For the enantioselective Michael additions by donor activation: (a) Feringa, B. L.; Pineschi, M.; Arnold, L. K.; Yokoyama, H.; Hayasaka, T.; Ebihara, K. J. Org. Chem. 1988, 53, 4148-4149. (b) Kumamoto, T.; Aoki, S.; Nakajima, M.; Koga, K. Tetrahedron: Asymmetry 1994, 5, 1431-1432. (c) Yamaguchi, M.; Shiraishi, T.; Igarashi, Y.; Hirama, M. Tetrahedron Lett. 1994, 35, 8233-8236. (d) Yamaguchi, M.; Shiraishi, T.; Hirama, M. J. Org. Chem. 1996, 61, 3520-3530 and references therein. (e) Inagaki, K.; Nozaki, K.; Takaya, H. Synlett 1997, 119-120. (f) Alexakis, A.; Vastra, J.; Manganey, P. Tetrahedron Lett. 1997, 38, 7745-7748. (g) Alexakis, A.; Vastra, J.; Burton, J.; Manganey, P. Tetrahedron: Asymmetry 1997, 8, 3193-3196. (h) Bako, P.; Kiss, T.; Take, L. Tetrahedron Lett. 1997, 38, 7259-7262. (i) Arai, T.; Sasai, H.; Yamaguchi, K.; Shibasaki, M. J. Am. Chem. Soc. 1998, 120, 441-442. (j) Hamashima, Y.; Hotta, D.; Sodeoka, M. J. Am. Chem. Soc. 2002, 124, 11240-11241.

12) Enantioselective Michael additions of silyl enolates or ketene silyl acetals: (a) Kobayashi, S.; Suda, S.; Yamada, M.; Mukaiyama, T. Chem. Lett. 1994, 97-100 and references cited therein. (b) Bernardi, A.; Colombo, G.; Scolastico, C. Tetrahedron Lett. 1996, 37, 8921-8924. (c) Bernardi, A.; Karamfilova, K.; Sanguinetti, S.; Scolastico, C. Tetrahedron 1997, 53, 1300913026. (d) Kitajima, H.; Katsuki, T. Synlett 1997, 568-570. (e) Evans, D. A.; Rovis, T.; Kozlowski, M. C.; Tedrow, J. S. J. Am. Chem. Soc. 1999, 121, 1994-1995. (f) Evans, D. A.; Willis, M. C.; Johnston, J. N. Org. Lett., 1999, 11, 865-868. (g) Evans, D. A.; Scheidt, K. A.; Johnston, J. N.; Willis, M. C. J. Am. Chem. Soc. 2001, 123, 4480-4491.

13) (a) Manickam, G.; Sandararajan, G. Tetrahedron: Asymmetry 1997, 8, 2271-2278. (b) Yamada, K.; Arai, T.; Sasai, H.; Shibasaki, M. J. Org. Chem. 1998, 63, 3666-3672. (c) Zhou, J.; Tang, Y. J. Am. Chem. Soc. 2002, 124, 9030-9031.

14) (a) Arai, T.; Sasai, H.; Aoe, K.; Okamura, K.; Date, T.; Shibasaki, M. Angew. Chem., Int. Ed. Engl. 1996, 35, 104-106. (b) Shibasaki, M.; Sasai, H.; Arai, T.; Iida, T. Pure Appl. Chem. 1998, 70, 1027-1034 and references therein. (c) Funabashi, K.; Saida, Y.; Kanai, M.; Arai, T.; Sasai, H.; Shibasaki, M. Tetrahedron Lett. 1998, 39, 7557-7558. (d) Kim, Y.-S.; Matsunaga, S.; Das, J.; Sekine, A.; Ohshima, T.; Shibasaki, M. J. Am. Chem. Soc. 2000, 122, 6506-6507. (e) Kumagai, N.; Matsunaga, S.; Shibasaki, M. Org. Lett. 2001, 3, 4251-4254. (f) Xu, Y.; Ohori, K.; Ohshima, T.; Shibasaki, M. Tetrahedron 2002, 58, 25852588. (g) Ohshima, T.; Xu, Y.; Takita, R.; Shimizu, S.; Zhong, D.; Shibasaki, M. J. Am. Chem. Soc. 2002, 124, 14546-14547. (h) Takita, R.; Ohshima, T.; Shibasaki, M. Tetrahedron Lett. 2002, 43, 4661-4665.

15) (a) End, N.; Macko, L.; Zehnder, M.; Pfaltz, A. Chem. Eur. J. 1988, 4, 818-824. (b) Nishiwaki, N.; Knudsen, K. R.; Gothelf, K. V.; Jørgensen, K. A. Angew. Chem. Int. Ed. 2001, 40, 29922995.

16) Intramolecular protonation has been involved in an enantioselective sequence of Michael addition / cyclization reactions of cyclic 1,3-diketones producing enol lactones under the double catalytic activation conditions (Ito, K.; Kanemasa, S. Unpublished results).

17) Nitro aldol reactions: (a) Trost, B. M.; Yeh, V. S. C. Angew Chem. Int. Ed. 2002, 41, 861-863; (b) Shibasaki, M.; Sasai, H.; Arai, T. Angew Chem. Int. Ed. Engl. 1997, 36, 1236-1256.

18) Kanemasa, S.; Kanai, T. J. Am. Chem. Soc. 2000, 122, 1071010711.

19) For enantioselective conjugate additions of nitroalkanes, see: chiral crown catalysis: (a) Bakó, P.; Szöllõsy, Á; Bombicz, P.; Tõke, L. Synlett. 1997, 291-292. (b) Bakó, P.; Novák, T.; Ludányi, K.; Pete, B.; Tõke, L.; Keglevich, G. Tetrahedron: Asymm. 1999, 10, 2373-2380. chiral alkaloid catalysis: (c) Matsumoto, K.; Uchida, T. Chem. Lett. 1981, 1673-1676. (d) Sera, A.; Takagi, K.; Katayama, H.; Yamada, H.; Matsumoto, K. $J$. Org. Chem. 1988, 53, 1157-1161. chiral phase transfer catalysis: (e) Colonna, S.; Hiemstra, H.; Wynberg, H. J. Chem. Soc., Chem. Commun. 1978, 238-239. (f) Colonna, S.; Re, A. J. Chem. 
Soc., Perkin. Trans. 1. 1981, 547-552. rubidium prolinate catalysis: (g) Yamaguchi, M.; Igarashi, Y.; Reddy, R. S.; Shiraishi, T.; Hirama, M. Tetrahedron. 1997, 53, 11223. proline catalysis: (h) Hanessian, S.; Pham, V. Org. Lett. 2000, 2, 2975-2978. prolinol $\cdot \mathrm{Ni}(\mathrm{II})$ complex or diamine $\mathrm{Co}(\mathrm{II})$ complex catalysis: (i) Botteghi, C.; Paganelli, S.; Schionato, A.; Boga, C.; Fava, A. J. Mol. Cat. 1991, 66, 7-21.

20) Perlmutter, P. Conjugate Addition Reactions in Organic Synthesis; Pergamon: Oxford, 1992.

21) (a) Mulzer, J.; Zuhse, R.; Schmiechen, R. Angew. Chem. Int. Ed. 1992, 31, 870-872. (b) Meyers, A. I.; Snyder, L. J. Org. Chem. 1993, 58, 36-42. (c) Baures, P. W.; Eggleston, D. S.; Erhard, K. F.; Cieslinski, L. B.; Torphy, T. J.; Christensen, S. B. J. Med. Chem. 1993, 36, 3274-3277. (d) Braun, M.; Opdenbusch, K.; Unger, C. Synlett. 1995, 1174-1176. (e) Diaz, A.; Siro, J. G.; Grancía-Navío, J. L.; Vaquero, J. J.; Alvarez-Builla, J. Synthesis. 1997, 559. (f) Honda, T.; Ishikawa, F.; Kanai, K.; Sato, S.; Kato. D.; Tominaga, H. Heterocycles. 1996, 42, 109. (g) Anada, M.; Mita, O.; Watanabe, H.; Kitagaki, S.; Hashimoto, S. Synlett. 1999, 1775-1777.

22) (R)-(-)-Rolipram (16) was purified by crystallization from AcOEt / hexane $\left(>99 \%\right.$ ee). $[\alpha]_{\mathrm{D}}-33.9^{\circ}$ (c $\left.1.09, \mathrm{MeOH}\right)$.

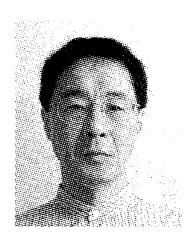

Shuji Kanemasa is Professor of organic chemistry at Kyushu University. He was born in Hiroshima in 1943 and received his M.D. in 1968 from Kyushu University. After spending five years as Assistant Professor in the research group of Professor O. Tsuge in the Industrial Institute of Science, Kyushu University, he received his $\mathrm{Ph}$.D. in 1974 from Kyushu University. He spent 7 years at Yamaguchi University as Associate Professor and returned to Kyushu University in 1981. Since 1988 he has been Full Professor at the Institute of Advanced Material Study. He worked as a postdoctral associate at Rensselaer Polytechnic Institute with Prof. K. T. Potts (1977-1978) and at New Mexico State University with Prof. W. Lwowski (19781979). His research interests include the areas of synthetic organic chemistry, heterocyclic chemistry, and catalyst design. 